\title{
Antimicrobial Activity and Phytochemical Screening of Aloe vera (Aloe barbadensis Miller)
}

\section{Darshan Dharajiya ${ }^{1}$, Nalin Pagi ${ }^{2}$, Hitesh Jasani ${ }^{3}$ and Payal Patel ${ }^{4}$}

${ }^{1}$ Department of Plant Molecular Biology and Biotechnology, C. P. College of Agriculture, Sardarkrushinagar Dantiwada Agricultural University, Sardarkrushinagar-385506, Gujarat, India

${ }^{2}$ Department of Genetics and Plant Breeding, CPCA, SDAU, Sardarkrushinagar-385506, Gujarat, India

${ }^{3}$ Department of Microbiology, College of Computer, Science and Information Technology (CCSIT), Junagadh-362015, Gujarat, India

${ }^{4}$ Department of Biotechnology, ARIBAS, New V.V.Nagar-388121, Gujarat, India *Corresponding author

\section{A B S T R A C T}

\section{Keywords \\ Antimicrobial activity, Aloe vera, A. barbadensis Miller, TLC Bioautography, Phytochemical analysis.}

Article Info

Accepted:

20 February 2017

Available Online:

10 March 2017
The present study was conducted to assess the antimicrobial potential and phytochemical analysis of Aloe vera (Aloe barbadensis Miller) leaves extracts. The extracts were prepared by the sequential cold maceration method by using hexane, ethyl acetate, methanol and distilled water as a solvent. Antimicrobial activity of four extracts was performed by agar well diffusion method against different bacteria and fungi. Determination of Minimum Inhibitory Concentration (MIC) of different extracts, Thin Layer Chromatography (TLC), TLC bioautography and qualitative phytochemical analysis were also performed.The antimicrobial activity of $A$. barbadensis leaves extracts was found maximum against $S$. marcescens with a Zone of Inhibition (ZOI) of $13.67 \pm 0.57 \mathrm{~mm}$ by hexane extract.The MIC of different extracts ranged between 6.25 and $50.00 \mathrm{mg} / \mathrm{ml}$. Among all the fungi used in the study, all the three Aspergillus species were slightly inhibited by the specific extracts. The finding of TLC bioautography showed that compounds eluted at $R_{f} 0.65$ demonstrated strong antimicrobial activity whereas compounds eluted at $R_{f} 0.41$ and $R_{f} 0.82$ exhibited moderate antimicrobial activity against $S$. marcescens. Phytochemical analysis indicated the presence of phytochemicals present in various extracts. The results of the investigation clearly indicate that $A$. barbadensis leaves extract have a potential antimicrobial activity against various microorganisms due to the presence of various phytochemicals.

\section{Introduction}

The resistance of microorganisms against antimicrobial drugs is a major problem of recent times, which is increasing day by day (Cohen, 2000; Kumar et al., 2013). As synthetic antimicrobials or antibiotics have considerable side effects over natural antimicrobial agents it is compulsory need to search for drugs which are effective against a wide range of microorganisms with minimal or no side-effects (Shrikanth et al., 2015). To tackle this problem, medicinal plants with ethnobotanical importance can be act as a source for the identification of the new drugs. Medicinal plants are considered as the 
greatest pharmaceutical stores existing on the earth as they can produce eternal secondary phytochemicals having bioactive properties. These phytochemicals work efficiently to cure various diseases and illnesses since ancient times (Abdallah, 2011).

Aloe barbadensis Miller (Aloe vera L.) is an herb found all over the world. It is revealed that it has conspicuous pharmacological activities such as antibacterial (Subramanian et al., 2006; Arunkumar and Muthuselvam, 2009; Saritha et al., 2010; Fani and Kohanteb, 2012; Nejatzadeh-Barandozi, 2013), antifungal (Bajwa et al., 2007; Rosca-Casian et al., 2007; Khaing, 2011; Sitara et al., 2011), antiviral (Zandi et al., 2007), antioxidant (Baradaran et al., 2013; Ray et al., 2013; Kang et al., 2014), cytotoxic (Jose et al., 2014; Shalabi et al., 2015), antidiabetic (Tanaka et al., 2006; Choudhary et al., 2014; Suleyman et al., 2014), anti-inflammatory (Vijayalakshmi et al., 2012; Bhattacharjee et al., 2014), antitumor (El-Shemy et al., 2010; Srihari et al., 2015), nephroprotective (Iftikhar et al., 2015; Virani et al., 2016), antiulcer (Borra et al., 2011) and anti-aging effects which can be used as a moisturizing agent to cure cardiovascular diseases as well as to enhance the immune system (Chatterjee et al., 2013). It is used as an herbal medicine since long time which contains more than 100 bioactive constituents. Aloe plant is a rich source of many natural phytochemicals possessing health-promoting effects like, anthraquinones, vitamins, minerals, polysaccharides, sterols, amino acids, saponins, salicylic acids and may more (Surjushe et al., 2008; Chatterjee et al., 2013).

This might be the first report of the evaluation of antimicrobial activity of $A$. barbadensis leaves extracts against two bacteria viz., Serratia marcescens and Bacillus cereus as well as four fungi used in the present study. Thus, the aim of the present investigation was to evaluate the inhibitory effects of $A$. barbadensis leaves extracts against pathogenic bacteria and fungus in addition to elucidate the possible class of phytochemicals responsible for their antimicrobial activity.

\section{Materials and Methods}

\section{Plant material used}

Fresh leaves of $A$. barbadensis were collected from the botanical garden of G. J. Patel Institute of Ayurvedic Studies and Research, New Vallabh Vidhyanagar, Gujarat, India. The taxonomical identification was done by the taxonomist. The fresh leaves were washed with distilled water and air dried. After drying, leaves were powdered and stored at $4^{\circ} \mathrm{C}$ in airtight bottles for further study.

\section{Preparation of plant extracts}

Four solvents viz., hexane, ethyl acetate, methanol and distilled water were used in the sequential cold maceration method (Dharajiya et al., 2014) as described in flow chart given in Figure 1. At the end of extraction process four different extracts were prepared and further used for antimicrobial study. Test samples of $100 \mathrm{mg}$ of extract $/ \mathrm{ml}$ of dimethyl sulphoxide (DMSO) were prepared to perform antimicrobial assay.

\section{Test microorganisms}

All the microorganisms used in the present study were collected from the Department of Microbiology, ARIBAS, Gujarat, India. Total four bacteria were used in the study, of which three were Gram negative bacteria viz., Escherichia coli (MTCC No. 448), Pseudomonas aeruginosa (MTCC No. 7436) and Serratia marcescens (MTCC No. 3124) while one was Gram positive bacterium namely, Bacillus cereus (MTCC No. 135). Total five fungal strains were used viz., 
Aspergillus niger, Aspergillus flavus, Aspergillus oryzae, Penicillium chrysogenum and Trichoderma viridae. The bacterial cultures were maintained on nutrient agar medium and the fungal strains were maintained on Potato Dextrose Agar (PDA) medium at $4^{\circ} \mathrm{C}$.

\section{Antimicrobial activity}

The antibacterial and antifungal activities of the extracts were carried out by agar well diffusion method as described by Dharajiya et al., 2014 and Dharajiya et al., 2015a.The positive control wells were filled with Gentamicin $(10 \mu \mathrm{g} / \mathrm{ml})$ and Fluconazole (10 $\mathrm{mcg} / \mathrm{disc})$ against bacteria and fungi, respectively. The negative control wells were filled with DMSO.

\section{Determination of Minimum Inhibitory Concentration (MIC)}

The determination of MIC of different extracts with respect to different bacteria and fungi was determined by using the broth dilution method as explained by Dharajiya et al., 2014.

\section{Analytical Thin Layer Chromatography (TLC)}

Analytical TLC was performed to identify an appropriate solvent system to generate the chromatogram. Various solvent systems were applied on the pre-coated TLC plates (Merck, silica gel $60 \mathrm{~F} 254$ plate, $0.25 \mathrm{~mm}$ ) for the development of the chromatogram.

Among all the solvent systems, chloroform: methanol: distilled water (50:40:10) was found best and used for the TLC analysis as well as TLC bioautography analysis. The TLC plates were visualized under visible light for compounds separated followed by the calculation of $R_{f}$ values.

\section{TLC Bioautography}

The hexane extract of $A$. barbadensis leaves was separated on TLC plate and the same plate was used for the TLC bioautography against $S$. marcescens. The TLC plate was developed using chloroform: methanol: distilled water (50:40:10) solvent, which separated components. The same TLC plate was dried at room temperature for the complete removal of solvents and placed in the petri plate followed by over laying of nutrient agar seeded with an overnight culture of $S$. marcescens. The petri plate was incubated at $37^{\circ} \mathrm{C}$ for $24 \mathrm{~h}$. After incubation, an aqueous solution of $5 \mathrm{mg} / \mathrm{ml}$ of methylthiazoletetrazolium (Sigma-Aldrich) was sprayed on the plate. The clear zone of inhibition was observed against pink/purple background and their $R_{f}$ values were compared with the reference TLC plate (Dharajiya et al., 2016).

\section{Qualitative phytochemical analysis}

The extracts were tested for the presence of alkaloids, tannins, saponins, cardiac glycosides, steroids, phenols and flavonoids according to the standard protocols for detecting the presence of different phytochemicals in the plant extracts as described by Dharajiya et al., 2012 and Dharajiya et al., 2015b.

\section{Results and Discussion}

The problem of microbial resistance towards antimicrobial drugs is becoming a major problem for humankind as it leads to the death of millions of people (Cohen, 2000). Most of the world's population relies on plant derived traditional medicines for the need of their primary health care (Duraipandian et al., 2006). Plants can be a very important source of newer drugs or antimicrobial compounds as they exhibit a vast range of 
phytochemicals. Various Aloe species are found all over the world which are used in cosmetics, medicine/pharma and food industry (Park and Jo, 2006). Aloe leaves contain various chemicals from different classes which have antimicrobial activity (Arunkumar and Muthuselvam, 2009). Hence, the present study was carried out to evaluate the efficiency of different four extracts as an antimicrobial agent as well as to access the presence of phytochemicals in each extract.

\section{Antimicrobial activity}

Antimicrobial activity (in terms of the zone of inhibition) of the extracts was evaluated against selected pathogenic bacterial and fungal strains by agar well diffusion method. In the present investigation, total four extracts viz., hexane, ethyl acetate, methanol and aqueous extracts of $A$. barbadensis leaves with a concentration of $100 \mathrm{mg} / \mathrm{ml}$ were tried. All the extracts except ethyl acetate showed antimicrobial activity against different test microorganisms. The maximum antibacterial effect of $A$. barbadensis leaves extracts was found against $S$. marcescens [Zone of inhibition $(\mathrm{ZOI})=13.67 \pm 0.57 \mathrm{~mm}]$ by hexane extract followed by inhibition of $B$. cereus $(\mathrm{ZOI}=12.33 \pm 0.57 \mathrm{~mm})$ by the methanol extract. The methanol extract showed inhibitory effect against all the tested bacterial strains while ethyl acetate extract failed to inhibit the growth of any of the bacterial strains evaluated in the present study. In case of antifungal activity, the maximum inhibitory activity was found by aqueous extract against $A$. niger with $09.6 \pm 0.57 \mathrm{~mm}$ zone of inhibition. Out of the four extracts tested, two extracts viz., hexane and ethyl acetate failed to express antifungal activity against any of the fungal strains use in the study. The methanol extract exhibited slight inhibitory action against $A$. oryzae. Out of all the microorganisms, $P$. chrysogenum and $T$. viridae were found to be resistant to all the four extracts of $A$. barbadensis leaves. The complete findings regarding antimicrobial activity are represented in Table 1 .

The inhibitory activities of $A$. barbadensis or Aloe vera leaves against some bacteria viz., Aeromonas hydrophius, Aggregatibacter actinomycetemcomitans, Bacillus sphaericus, Bacteroides fragilis, Enterococcus faecalis, Escherichia coli, Klebsiella pneumoniae, Listeria monocytogenes, Micrococcus luteus, Morganella morganii, Mycobacterium smegmatis, Porphyromonas gingivalis, Proteus mirabilis, Proteus vulgaris, Pseudomonas aeruginosa, Shigella boydii, Staphylococcus aureus, Streptococcus mutans, Streptococcus pyogenes and Vibrio parahaemolyticus have been evaluated (Alemdar and Agaoglu, 2009; Arunkumar and Muthuselvam, 2009; Pandey and Mishra, 2010; Saritha et al., 2010; Fani and Kohanteb, 2012; Nejatzadeh-Barandozi, 2013) in the recent past.

There are very few reports on antifungal activity of Aloe sp. which included the antifungal activity against some fungi viz., Alternaria alternata, Aspergillus flavus, Aspergillus niger, Botrytis gladiolorum, Candida albicans, Colletotrichum coccodes, Crytococcus neoformans, Drechslera hawaiensis, Fusarium oxysporum, Heterosporium pruneti, Microsporium canis, Penicillium gladioli, Penicillium maneffei, Penicillum digitatum, Phythium sp., Rhizoctonia solani, Trichophyton mentagraphytes and Trichophyton schoenleini (Agarry and Olaleye, 2005; De Rodriguez et al., 2005; Rosca-Casian et al., 2007; Alemdar and Agaoglu, 2009; Khaing, 2011; Sitara et al., 2011).

Hence, possibly it is the first study showing antimicrobial activity of $A$. barbadensis leaves extracts against two bacteria viz., $S$. marcescens and B. cereus as well as four 
fungal strains viz., Aspergillus flavus, Aspergillus oryzae, Penicillium chrysogenum and Trichoderma viridae.

\section{Determination of MIC}

The MIC values of various extracts with respect to specific microorganism were resolute using the broth dilution method as given in Table 2. All the extracts exhibiting antimicrobial activity in the agar well diffusion method were advanced to determine MIC values. As per the MIC results found in the present study, the range of MIC of various extracts was 6.25 to $50.00 \mathrm{mg} / \mathrm{ml}$. In the present investigation, the lowest MIC value recorded was $6.25 \mathrm{mg} / \mathrm{ml}$ for the hexane extract against $S$. marcescens which indicated maximum power to inhibit the growth of the specific bacterial strain. The highest MIC value was $50 \mathrm{mg} / \mathrm{ml}$ for methanol and aqueous extracts against $A$. oryzae and $A$. flavus, respectively.

There are few reports of determination of MIC of various extracts of Aloe sp. against different bacterial strains. One of the previous study indicated that the range of MIC of $A$. vera gel was $12.5-50.0 \mu \mathrm{g} / \mathrm{ml}$ against some periodontopathic and cariogenic bacterial isolates (Fani and Kohanteb, 2012). Another report revealed that the range of MIC of $A$. barbadensis extract against various pathogenic bacteria was $0.10-10.0 \mathrm{mg} / \mathrm{ml}$ (Pandey and Mishra, 2010). Ultimately, there are very few reports of MIC determination for A. barbadensis leaf extracts against the strains used in the present study. Hence, present study can be utilized as a base for the development of the antimicrobial drugs from A. barbadensis leaf against some bacteria.

\section{TLC and TLC Bioautography}

Total five components from hexane extract of A. barbadensis leaves were separated by TLC and their $\mathrm{R}_{\mathrm{f}}$ values are given in Table 3 . The same plate was used for the TLC bioautography against $S$. marcescens. It allowed determining the active components of the hexane extract having antimicrobial activity against $S$. marcescens.

Table.1 Antimicrobial activity (Zone of Inhibition) of $A$. barbadensis leaves extracts

\begin{tabular}{|c|c|c|c|c|c|c|c|c|}
\hline \multirow{2}{*}{\multicolumn{2}{|c|}{ Microorganisms }} & \multicolumn{4}{|c|}{$\begin{array}{c}\text { Name of extract } \\
\text { (Concentration }=100 \mathrm{mg} / \mathrm{ml})\end{array}$} & \multicolumn{2}{|c|}{ Positive control } & \multirow{2}{*}{$\begin{array}{c}\begin{array}{c}\text { Negative } \\
\text { control }\end{array} \\
\text { DMSO }\end{array}$} \\
\hline & & Hexane & $\begin{array}{l}\text { Ethyl } \\
\text { Acetate }\end{array}$ & Methanol & Aqueous & $\begin{array}{c}\text { Gentamicin } \\
(10 \mu \mathrm{g} / \mathrm{ml})\end{array}$ & $\begin{array}{l}\text { Fluconazole } \\
(10 \mathrm{mcg} / \text { disc })\end{array}$ & \\
\hline \multirow{4}{*}{ 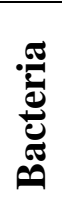 } & S. marcescens & $13.67 \pm 0.57$ & - & $11.00 \pm 1.00$ & $11.67 \pm 1.15$ & $19.00 \pm 1.00$ & NA & - \\
\hline & B. cereus & - & - & $12.33 \pm 0.57$ & $10.83 \pm 0.76$ & $15.17 \pm 0.76$ & NA & - \\
\hline & $P$. aeruginosa & - & - & $08.83 \pm 0.76$ & - & $15.00 \pm 1.00$ & NA & - \\
\hline & E. coli & - & - & $10.33 \pm 0.57$ & $09.5 \pm 0.50$ & $14.67 \pm 1.04$ & NA & - \\
\hline \multirow{5}{*}{ 苞 } & A. niger & - & - & - & $09.6 \pm 0.57$ & NA & $16.16 \pm 1.04$ & - \\
\hline & A. flavus & - & - & - & $08.1 \pm 0.28$ & NA & $21.33 \pm 1.15$ & - \\
\hline & A. oryzae & - & - & $08.6 \pm 0.57$ & - & NA & $16.00 \pm 1.00$ & - \\
\hline & P. chrysogenum & - & - & - & - & NA & $18.66 \pm 1.52$ & - \\
\hline & T. viridae & - & - & - & - & NA & $22.33 \pm 0.57$ & - \\
\hline
\end{tabular}


Table.2 Minimum Inhibitory Concentration (MIC) values of A. barbadensis leaves extracts

\begin{tabular}{|c|c|c|c|c|c|}
\hline \multirow{2}{*}{\multicolumn{2}{|c|}{ Microorganisms }} & \multicolumn{4}{|c|}{ Name of extract } \\
\hline & & \multirow{2}{*}{$\begin{array}{l}\text { Hexane } \\
06.25\end{array}$} & \multirow{2}{*}{$\begin{array}{c}\text { Ethyl Acetate } \\
\text { NA }\end{array}$} & \multirow{2}{*}{\begin{tabular}{|c|} 
Methanol \\
12.50
\end{tabular}} & \multirow{2}{*}{$\begin{array}{c}\text { Aqueous } \\
12.50\end{array}$} \\
\hline \multirow{4}{*}{ 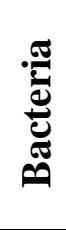 } & S. marcescens & & & & \\
\hline & B. cereus & NA & NA & 12.50 & 25.00 \\
\hline & P. aeruginosa & NA & NA & 25.00 & NA \\
\hline & E. coli & NA & NA & 25.00 & 25.00 \\
\hline \multirow{5}{*}{ 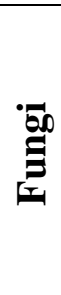 } & A. niger & NA & NA & NA & 25.00 \\
\hline & A. flavus & NA & NA & NA & 50.00 \\
\hline & A. oryzae & NA & NA & 50.00 & NA \\
\hline & P. chrysogenum & NA & NA & NA & NA \\
\hline & T. viridae & NA & NA & NA & NA \\
\hline
\end{tabular}

Table.3 Thin Layer Chromatography (TLC) of hexane extract of A. barbadensis leaves

\begin{tabular}{|c|c|c|}
\hline No. of Compound & $\mathbf{R}_{\mathbf{f}}$ value & Band colour in visible light \\
\hline 1 & 0.35 & Dark brown \\
\hline 2 & 0.41 & Brown \\
\hline 3 & 0.65 & Light yellow \\
\hline 4 & 0.82 & Brown \\
\hline 5 & 0.90 & Brown \\
\hline
\end{tabular}

Table.4 Qualitative phytochemical analysis of A. barbadensis leaves extracts

\begin{tabular}{|c|c|c|c|c|}
\hline \multirow{2}{*}{ Name of test } & \multicolumn{4}{|c|}{ Name of extract } \\
\cline { 2 - 5 } & Hexane & Ethyl Acetate & Methanol & Aqueous \\
\hline Alkaloids & + & - & + & + \\
\hline Saponins & + & + & + & - \\
\hline Tannins & - & - & - & + \\
\hline Sterols & + & + & + & + \\
\hline Cardiac glycoside & - & - & - & - \\
\hline Flavanoids & - & - & + & + \\
\hline Phenol & + & + & + & + \\
\hline (+): Present, (-): Absence & & & & \\
\hline
\end{tabular}


Fig.1 Sequential cold maceration method for preparation of plant extracts

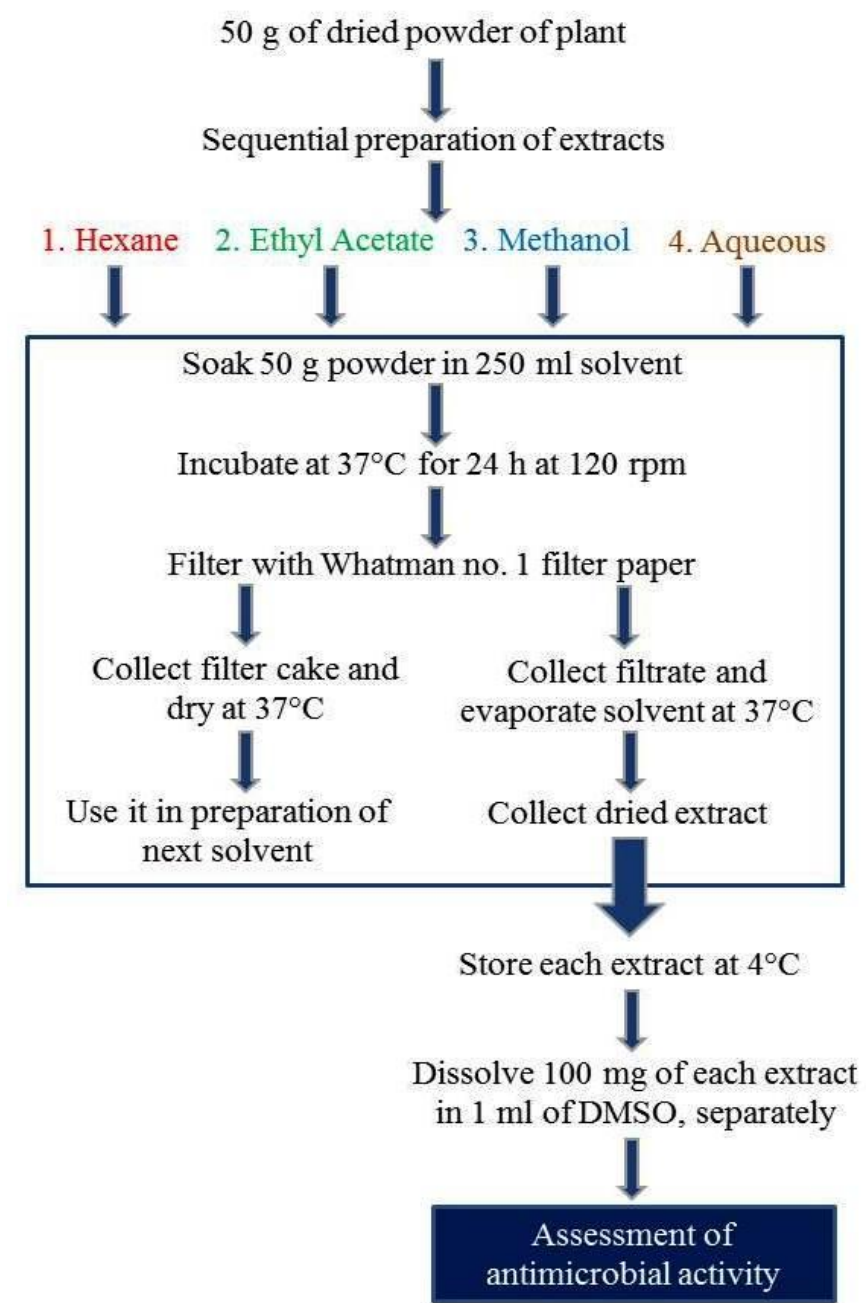

Fig.2 TLC bioautography of hexane extract of $A$. barbadensis leaves against $S$. marcescens

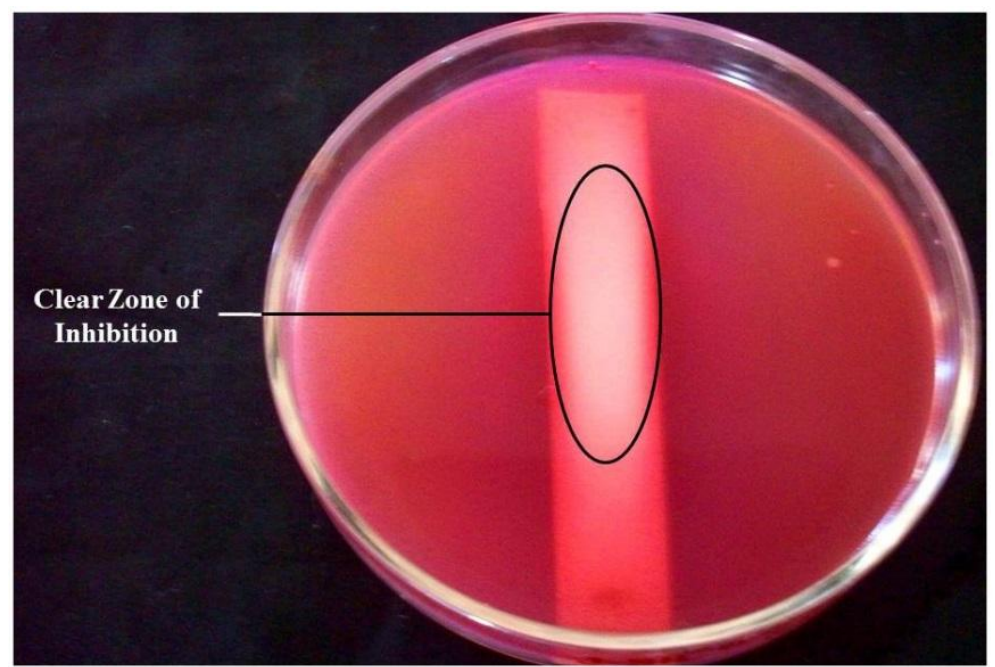


The result of TLC bioautography represented that components separated at $R_{f} \quad 0.65$ possessed strong antimicrobial activity, whereas components with 0.41 and $0.82 \mathrm{R}_{\mathrm{f}}$ values exhibited moderate antimicrobial activity against $S$. marcescens which is represented as a clear zone of inhibition in Figure 2. Hence, the components with specific $R_{f}$ values and having antimicrobial activity can be detected and purified for further specific analysis. The ethanol, acetone and methanol extracts of $A$. vera gel were used for the separation of the active components possessing antimicrobial activity (Lawrence et al., 2009). Another study revealed that the component with $0.8 \mathrm{R}_{\mathrm{f}}$ value exhibited antimicrobial activity and identified as aloe-emodin (Nidiry et al., 2011). In the present investigation, the component with $0.82 R_{f}$ value possessed antimicrobial activity which is indicative of the extraction of aloeemodin in the hexane and other extracts showing antimicrobial activity.

\section{Qualitative phytochemical analysis}

The preliminary phytochemical analysis gives valuable information regarding the presence of important classes of phytochemicals present in the extracts. The outcomes of the qualitative phytochemical analysis of various extracts of $A$. barbadensis leaves are given in Table 4. The results point out to the presence of some phytochemicals in methanol, aqueous and hexane extracts as compared to ethyl acetate extract. It might be the reason behind no antimicrobial activity of ethyl acetate extract against the selected microorganisms. Similar investigations were carried out by other researchers for the determination of the class of phytochemicals present in various extracts of Aloe species (Arunkumar and Muthuselvam, 2009; Raphael, 2012).

In Conclusion, the current study revealed that the methanol extract of $A$. barbadensis leaves possessed overall more antimicrobial activity followed by aqueous and hexane extracts, however hexane extract showed antimicrobial activity only against $S$. marcescens but with maximum zone of inhibition. Various phytochemicals may play role as antimicrobial agent which were extracted in different solvents. These phytochemicals having antimicrobial activity should be identified and purified from the crude extracts by various analytical techniques and can be implicated in the development of antimicrobial drugs against various pathogenic microorganisms.

\section{Acknowledgement}

We (authors) express our genuine appreciations to ARIBAS, New V.V. Nagar for the financial assistance and providing facilities to carry out the present investigation.

\section{References}

Abdallah, E.M. 2011. Plants: An alternative source for antimicrobials. J. Appl. Pharmaceutical Sci., 1(6): 16-20.

Agarry, O.O., and Olaleye, M.T. 2005. Comparative antimicrobial activities of Aloe vera gel and leaf. African J. Biotechnol., 4(12): 1413-1414.

Alemdar, S., and Agaoglu, S. 2009. Investigation of in vitro antimicrobial activity of Aloe vera juice. J. Animal and Veterinary $A d v ., 8(1)$ : 99-102.

Arunkumar, S., and Muthuselvam, M. 2009. Analysis of phytochemical constituents and antimicrobial activities of Aloe vera L. against clinical pathogens. World J. Agri. Sci., 5(5): 572-576.

Bajwa, R., Shafique, S., and Shafique, S. 2007. Appraisal of antifungal activity of Aloe vera. Mycopath, 5(1): 5-9.

Baradaran, A., Nasri, H., Nematbakhsh, M., and Rafieian-Kopaei, M. 2013. Antioxidant activity and preventive effect of aqueous leaf extract of Aloe 
vera on gentamicin-induced nephrotoxicity in male Wistar rats. $L a$ Clinica Terapeutica, 165(1): 7-11.

Bhattacharjee, S., Paul, S., Dutta, S., and Chaudhuri, T.K. 2014. Antiinflammatory and protective properties of Aloe vera leaf crude gel in carrageenan induced acute inflammatory rat models. Int. J. Pharmacy and Pharmaceutical Sci., 6(9): 368-371.

Borra, S.K., Lagisetty, R.K., and Mallela, G.R. 2011. Anti-ulcer effect of Aloe vera in non-steroidal anti-inflammatory drug induced peptic ulcers in rats. African J. Pharmacy and Pharmacol., 5(16), 1867-1871.

Chatterjee, P., Chakraborty, B., and Nandy, S. 2013. Aloe vera plant: review with significant pharmacological activities. Mintage J. Pharmaceutical and Med. Sci., 2(3): 21-24.

Choudhary, M., Kochhar, A., and Sangha, J. 2014. Hypoglycemic and hypolipidemic effect of Aloe vera L. in non-insulin dependent diabetics. J. Food Sci. Technol., 1(1): 90-96.

Cohen, M.L. 2000. Changing patterns of infectious disease. Nature, 406(6797): 762-767.

De Rodriguez, D.J., Hernández-Castillo, D., Rodriguez-Garcia, R., and AnguloSánchez, J.L. 2005. Antifungal activity in vitro of Aloe vera pulp and liquid fraction against plant pathogenic fungi. Industrial Crops and Products, 21(1): 81-87.

Dharajiya, D., Jasani, H., Khatrani, T., Kapuria, M., Pachchigar, K., and Patel, P. 2016. Evaluation of antibacterial and antifungal activity of fenugreek (Trigonella foenum-graecum) extracts. Int. J. Pharmacy and Pharmaceutical Sci., 8(4): 212-217.

Dharajiya, D., Khatrani, T., Patel, P., and Moitra, N. 2015a. Evaluation of antifungal activity of Emblica officinalis, Aloe vera and Vitex negundo extracts. J. Chemical, Biol. Physical Sci., 5(4): 3990-3996.

Dharajiya, D., Moitra, N., Patel, B., and Patel, R.K. 2012. Preliminary phytochemical analysis of the Indian medicinal plants for antibacterial activity against bovine mastitis pathogens. Wayamba J. Animal Sci., 4: Article No. 1342590628.

Dharajiya, D., Patel, P., and Moitra, N. 2015b. Antibacterial activity of Emblica officinalis (Gaertn.) Fruits and Vitex negundo (L.) Leaves. Current Trends in Biotechnol. Pharmacy, 9(4), 357-368.

Dharajiya, D., Patel, P., Patel, M., and Moitra, N. 2014. In vitro antimicrobial activity and qualitative phytochemical analysis of Withania somnifera (L.) Dunal extracts. Int. J. Pharmaceutical Sci. Review and Res., 27(2): 349-354.

Duraipandiyan, V., Ayyanar, M., and Ignacimuthu, S. 2006. Antimicrobial activity of some ethnomedicinal plants used by Paliyar tribe from Tamil Nadu, India. BMC Complementary and Alternative Med., 6(1): 35.

El-Shemy, H.A., Aboul-Soud, M.A.M., Nassr-Allah, A.A., Aboul-Enein, K.M., Kabash, A., and Yagi, A. 2010. Antitumor properties and modulation of antioxidant enzymes' activity by Aloe vera leaf active principles isolated via supercritical carbon dioxide extraction. Curr. Medicinal Chem., 17(2): 129-138.

Fani, M., and Kohanteb, J. 2012. Inhibitory activity of Aloe vera gel on some clinically isolated cariogenic and periodontopathic bacteria. J. Oral Sci., 54(1): 15-21.

Iftikhar, A., Hasan, I.J., Sarfraz, M., Jafri, L., and Ashraf, M.A. 2015. Nephroprotective effect of the leaves of Aloe barbadensis (Aloe vera) against toxicity induced by diclofenac sodium in albino rabbits. West Indian Med. J., 
64(5): 462-467.

Jose, J., Sudheesh, S., Sumesh Kumar, T.M., Sony, J., and Jayadevi Variyar, E. 2014. A comparative evaluation of anticancer activities of flavonoids isolated from Mimosa pudica, Aloe vera, Phyllanthus niruri against human breast carcinoma cell line (MCF-7) using MTT assay. Int. J. Pharmacy and Pharmaceutical Sci., 6(2): 319-322.

Kang, M.C., Kim, S.Y., Kim, Y.T., Kim, E.A., Lee, S.H., Ko, S.C., Wijesinghe, W.A.J.P., Samarakoon,K.W., Kim, Y.S., Cho, J.H., Jang, H.S., and Jeon, Y.J. 2014. In vitro and in vivo antioxidant activities of polysaccharide purified from aloe vera (Aloe barbadensis) gel. Carbohydrate Polymers, 99: 365-371.

Khaing, T.A. 2011. Evaluation of the antifungal and antioxidant activities of the leaf extract of Aloe vera (Aloe barbadensis Miller). World Academy of Science, Engineering and Technology, 75: 610-612.

Kumar, M., Nehra, K., and Duhan, J.S. 2013. Phytochemical analysis and antimicrobial efficacy of Leaf extracts of Pithecellobium dulce. Asian J. Pharmaceutical and Clinical Research, 6(1): 70-76.

Lawrence, R., Tripathi, P., and Jeyakumar, E. 2009. Isolation, purification and evaluation of antibacterial agents from Aloe vera. Brazilian J. Microbiology, 40(4): 906-915.

Nejatzadeh-Barandozi, F. 2013. Antibacterial activities and antioxidant capacity of Aloe vera. Organic and Medicinal Chemistry Letters, 3: 5.

Nidiry, E.S.J., Ganeshan, G., and Lokesha, A.N. 2011. Antifungal activity of some extractives and constituents of Aloe vera. Research J. Medicinal Plant, 5(2): 196-200.

Pandey, R., and Mishra, A. 2010.
Antibacterial activities of crude extract of Aloe barbadensis to clinically isolated bacterial pathogens. Applied Biochemistry and Biotechnology, 160(5): 1356-1361.

Park, Y.I., and Jo, T.H. 2006. Perspective of industrial application of Aloe vera. In: Park, Y.I., and Lee, S.K. (Ed.), New Perspectives on Aloe, first ed., Springer US, New York, pp. 191-200.

Raphael, E. 2012. Phytochemical constituents of some leaves extract of Aloe vera and Azadirachta indica plant species. Global Advanced Research J. Environmental Science and Toxicology, 1(2): 14-17.

Ray, A., Gupta, S.D., and Ghosh, S. 2013. Evaluation of anti-oxidative activity and UV absorption potential of the extracts of Aloe vera L. gel from different growth periods of plants. Industrial Crops and Products, 49: 712-719.

Rosca-Casian, O., Parvu, M., Vlase, L., nd Tamas, M. 2007. Antifungal activity of Aloe vera leaves. Fitoterapia, 78(3): 219-222.

Saritha, V., Anilakumar, K.R., and Khanum, F. 2010. Antioxidant and antibacterial activity of Aloe vera gel extracts. Int. J. Pharmaceutical and Biological Archive, 1(4): 376-384.

Shalabi, M., Khilo, K., Zakaria, M.M., Elsebaei, M.G., Abdo, W., and Awadin, W. 2015. Anticancer activity of Aloe vera and Calligonum comosum extracts separetely on hepatocellular carcinoma cells. Asian Pacific J. Tropical Biomedicine, 5(5): 375-381.

Shrikanth, V.M., Janardhan, B., Dhananjaya, B.L., Muddapura, U.M., and More, S.S. 2015. Antimicrobial and antioxidant activity of methanolic root extract of Tabernaemontana alternifolia L. Int. J. Pharmacy and Pharmaceutical Sci., 7(13): 66-69.

Sitara, U., Hassan, N., and Naseem, J. 2011. 
Antifungal activity of Aloe vera gel against plant pathogenic fungi. Pakistan J. Botany, 43(4): 2231-2233.

Srihari, R., Surendranath, A.R., Kasturacharya, N., Shivappa, K.C., Sivasitambaram, N.D., and Dhananjaya, B.L. 2015. Evaluating the cytotoxic potential of methonolic leaf extract of Aloe vera on MCF-7 breast cancer cell lines. Int. J. Pharmacy and Pharmaceutical Sci., 7(13): 81-83.

Subramanian, S., Kumar, D.S., Arulselvan, P., and Senthilkumar, G.P. 2006. In vitro antibacterial and antifungal activities of ethanolic extract of Aloe vera leaf gel. J. Plant Sci., 1(4): 348-355.

Suleyman, A., Gnanasekaran, N., and Daniel, S. 2014. Amelioration of streptozotocininduced hyperglycemia and dyslipidemia through Aloe debrana. Int. J. Pharmacy and Pharmaceutical Sci., 7(2): 290-293.

Surjushe, A., Vasani, R., and Saple, D.G. 2008. Aloe vera: A short review. Indian J. Dermatol., 53(4): 163-166.

Tanaka, M., Misawa, E., Ito, Y., Habara, N.,
Nomaguchi, K., Yamada, M., Toida, T., Hayasawa, H., Takase, M., Inagaki, M., and Higuchi, R. 2006. Identification of five phytosterols from Aloe vera gel as anti-diabetic compounds. Biol. Pharmaceutical Bulletin, 29(7): 14181422.

Vijayalakshmi, D., Dhandapani, R., Jayaveni, S., Jithendra, P.S., Rose, C., and Mandal, A.B. 2012. In vitro anti inflammatory activity of Aloe vera by down regulation of MMP-9 in peripheral blood mononuclear cells. $J$. Ethnopharmacol., 141(1): 542-546.

Virani, S., Bhatt, S., Saini, M., and Saxena, K. 2016. Aloe vera attenuates gentamicininduced nephrotoxicity in wistar albino rats: histopathological and biochemical changes. Asian J. Pharmaceutical and Clinical Res., 9(1): 113-117.

Zandi, K., Zadeh, M.A., Sartavi, K., and Rastian, Z. 2007. Antiviral activity of Aloe vera against herpes simplex virus type 2: An in vitro study. African J. Biotechnol., 6(15): 1770-1773.

\section{How to cite this article:}

Darshan Dharajiya, Nalin Pagi, Hitesh Jasani, Payal Patel. 2017. Antimicrobial Activity and Phytochemical Screening of Aloe vera (Aloe barbadensis Miller). Int.J.Curr.Microbiol.App.Sci. 6(3): 2152-2162. doi: https://doi.org/10.20546/ijcmas.2017.603.246 